\title{
RESULTADOS DE 4 ANOS DE UM PROGRAMA DE SEGURANÇA DO PACIENTE EM UMA REDE DE HOSPITAIS PÚBLICOS BRASILEIROS
}

Helaine Carneiro Capucho Lorena Bezerra Carvalho Marcia Amaral Dal Sasso Bruna Mafra Guedes Leili Mara Mateus da Cunha 


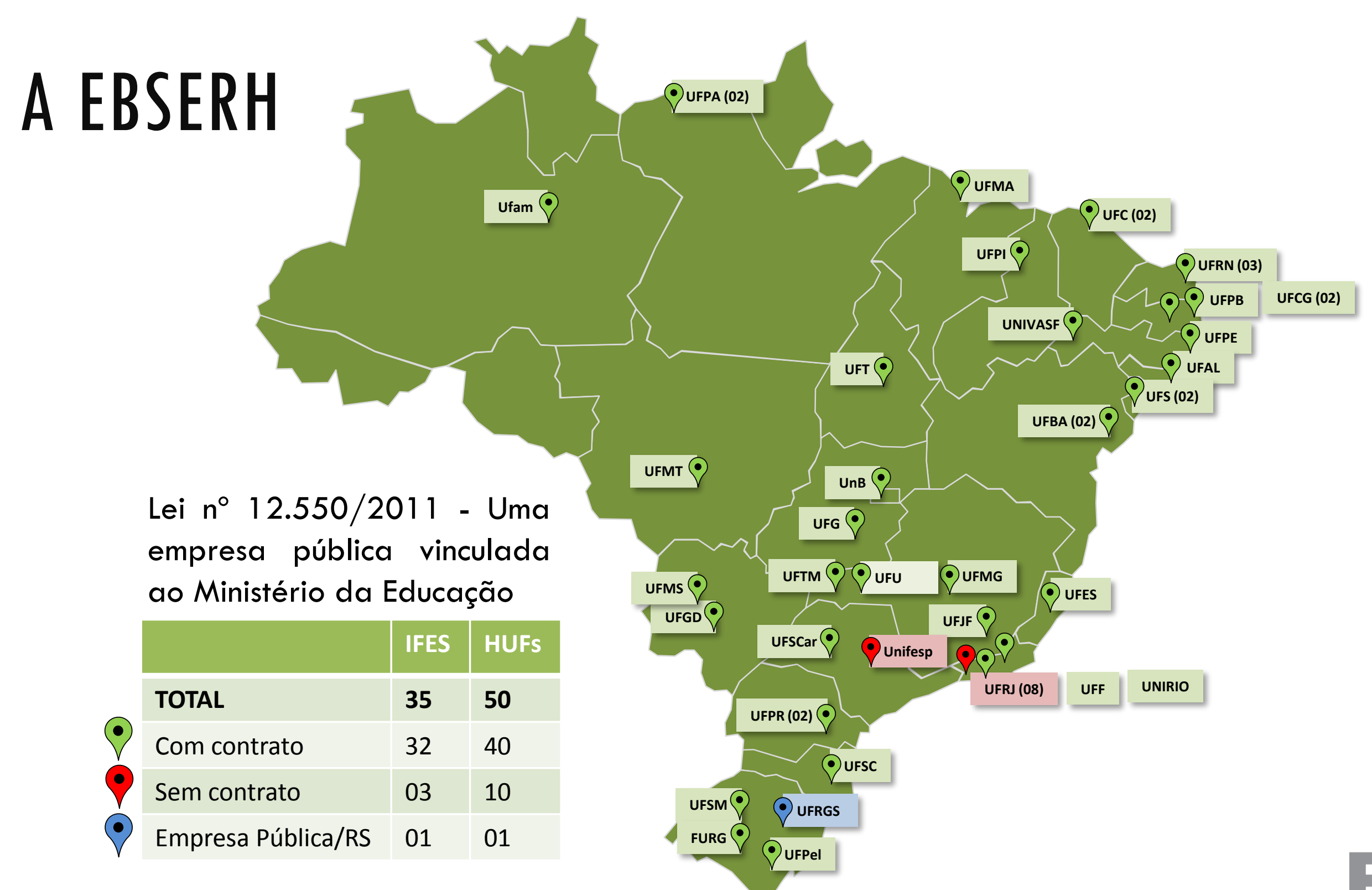

Quali : $\mathfrak{D}$

Lei $n^{\circ} 12.550 / 2011$ - Uma empresa pública vinculada ao Ministério da Educação

\begin{tabular}{|l|l|l|}
\hline Com contrato & 32 & 40 \\
\hline Sem contrato & 03 & 10 \\
\hline Empresa Pública/RS & 01 & 01 \\
\hline
\end{tabular}




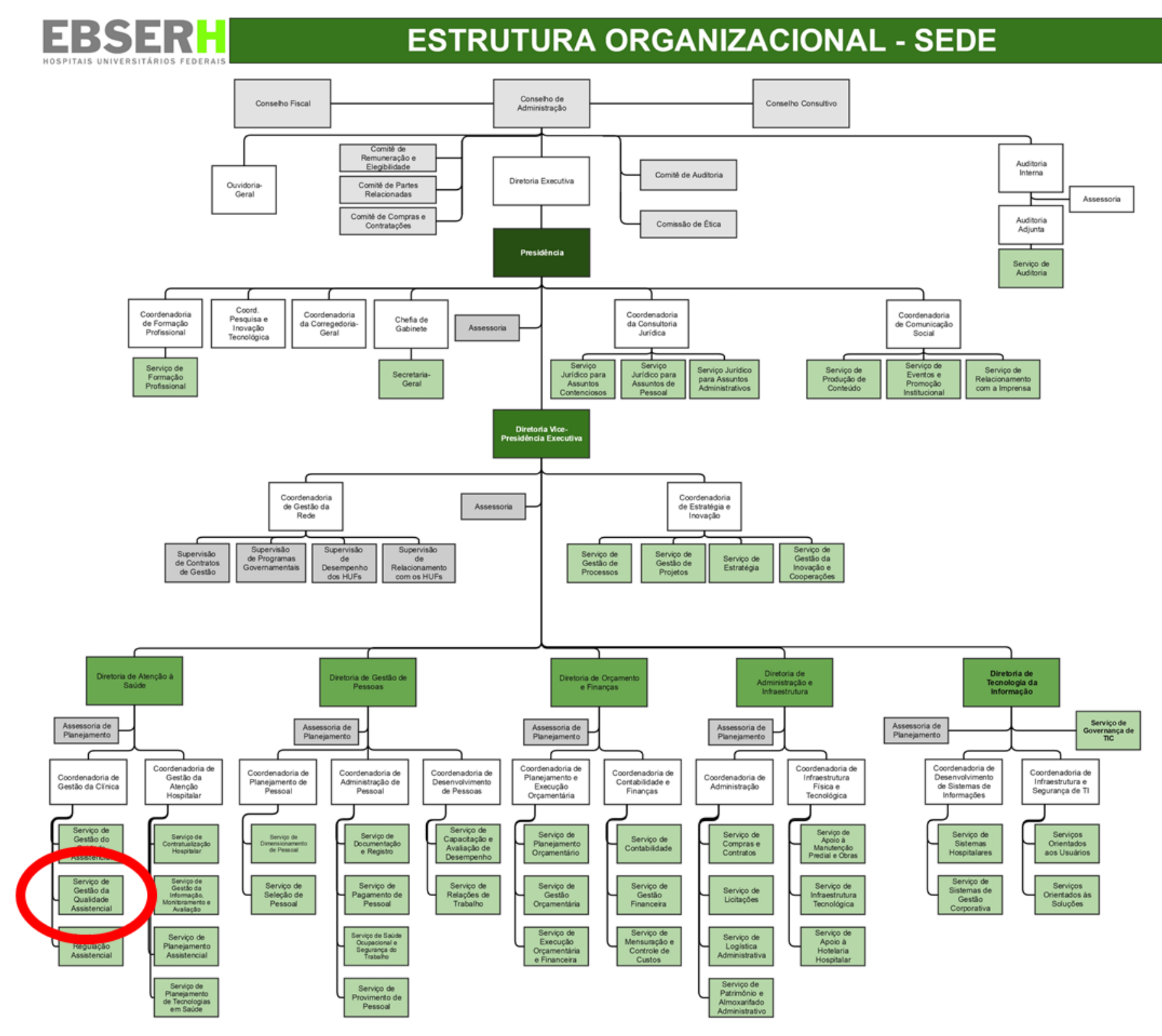




\section{O PROGRAMA EBSERH DE SEGURANÇA DO PACIENTE}

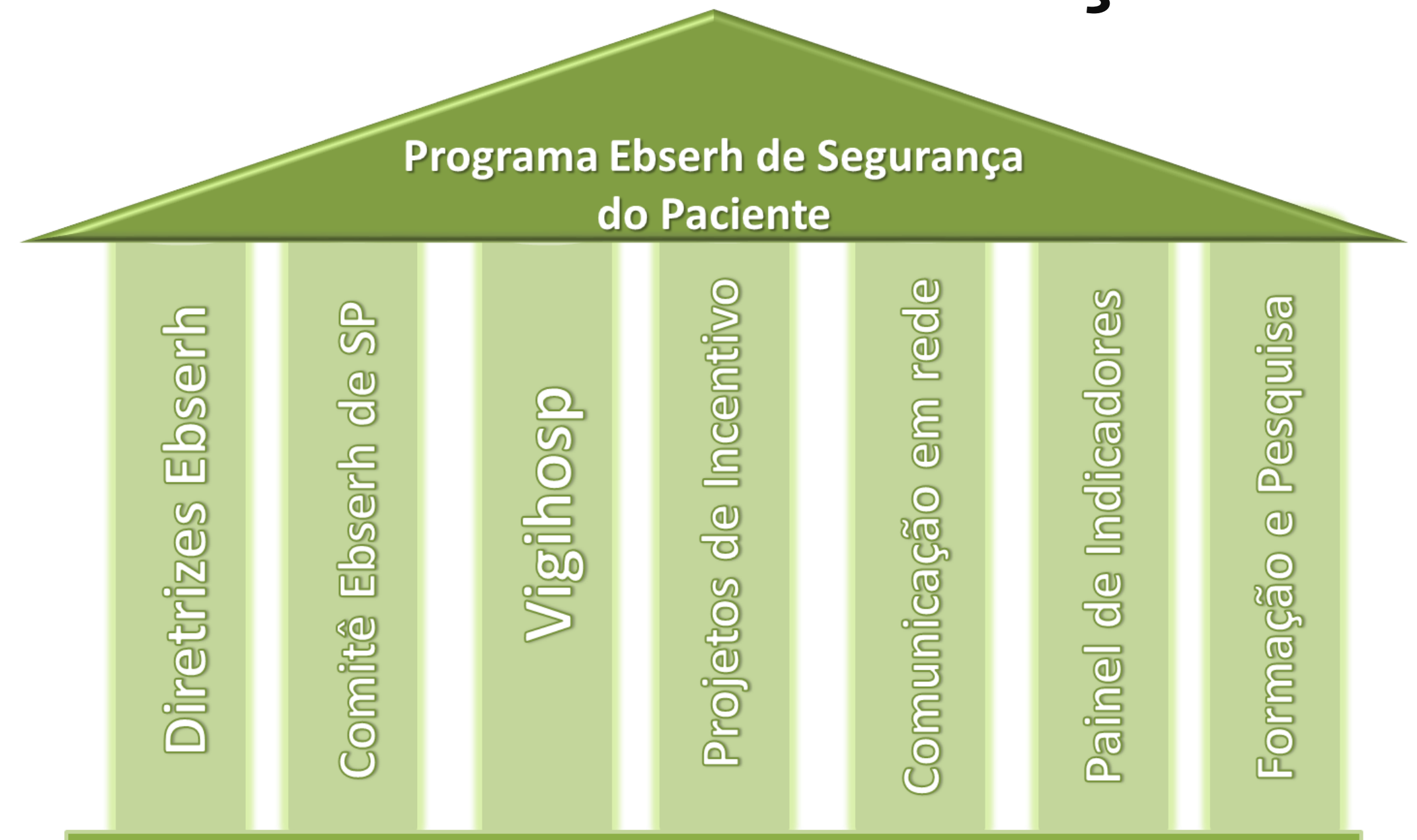




\section{Quali: 2}

\section{AÇõES}
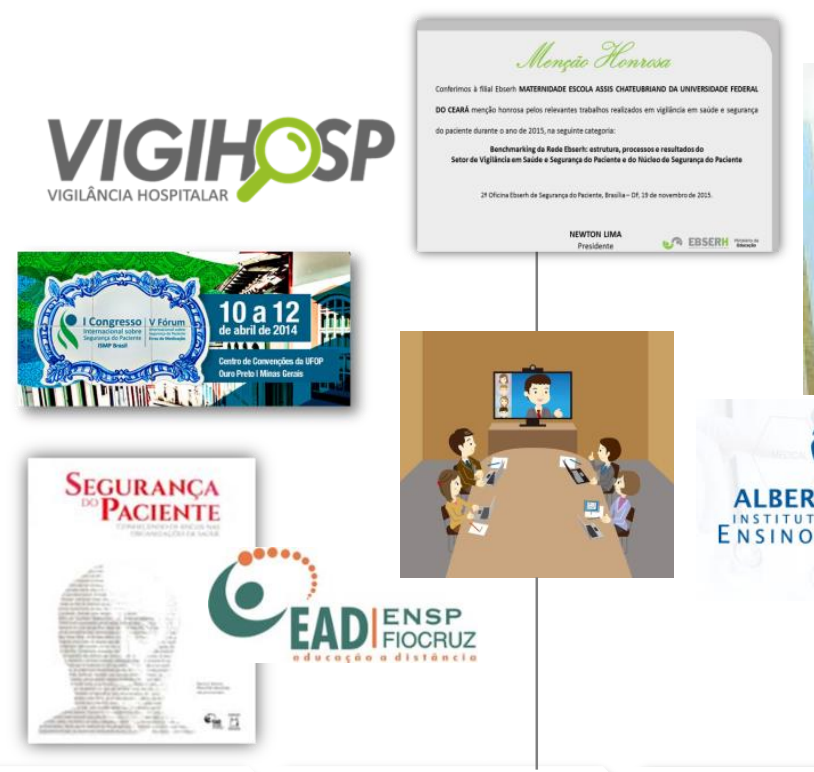

$-15$

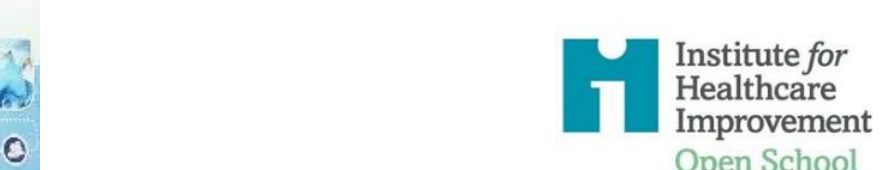

(1.) CENTRO DE
SIMULACÃO
REALISTICA
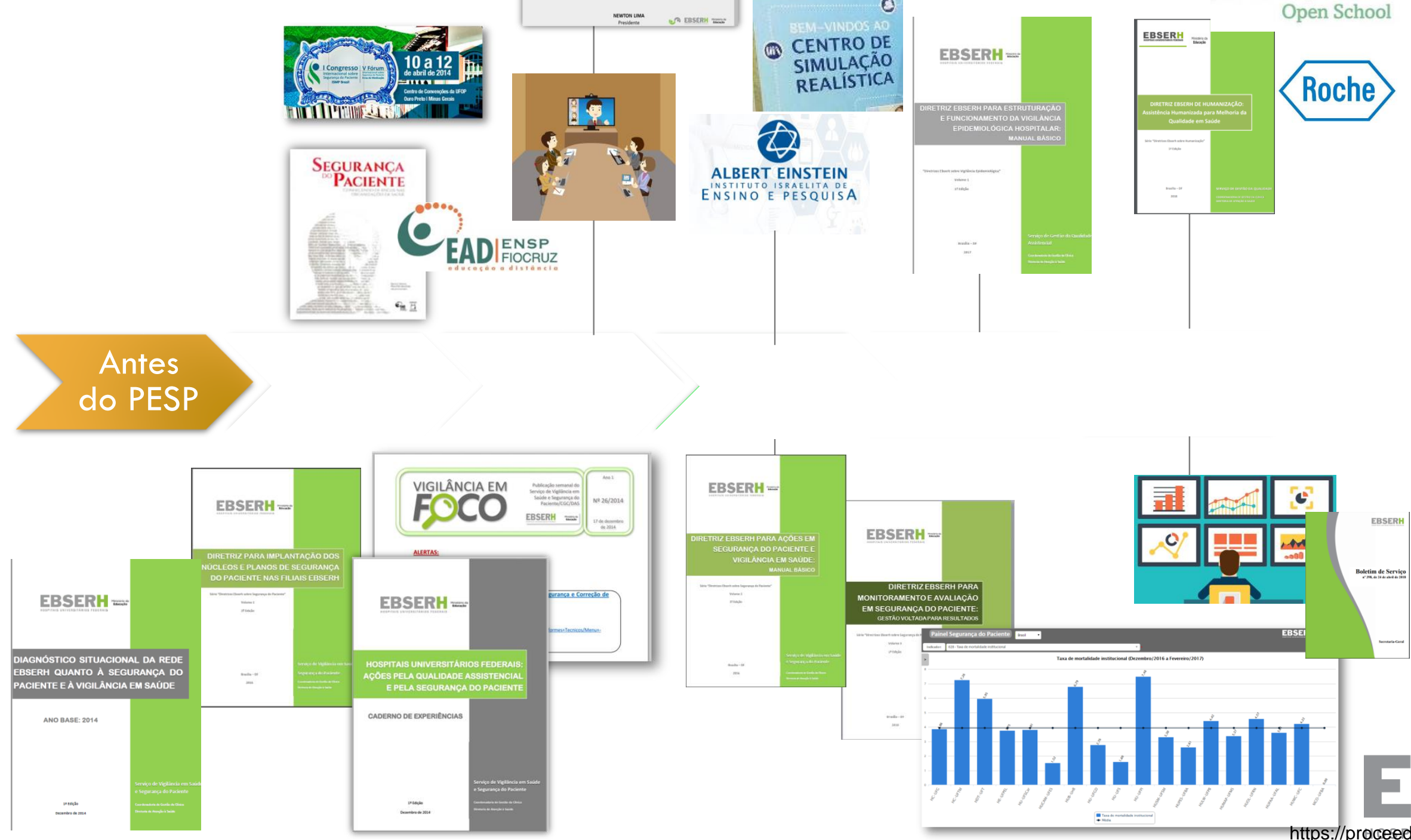


\section{OBJETIVO}

Avaliar indicadores de estrutura e processos de um programa de segurança do paciente (PESP) em 40 (quarenta) hospitais universitários federais (HUF), por meio da comparação da situação das instituições antes de entrar na rede de hospitais e em outubro de 2018. 


\section{RESULTADOS}

Antes do Programa de Segurança do Paciente

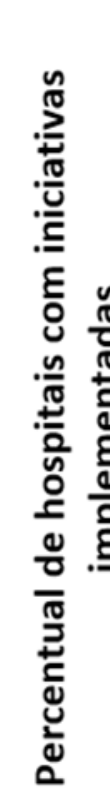

$100 \%$

$100 \%$

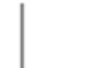

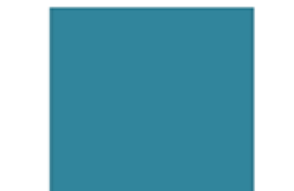

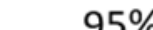

$95 \%$

Depois (out/2018)

Hosp
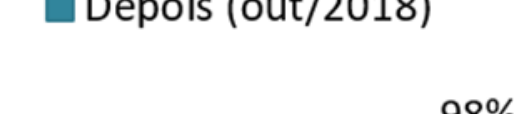


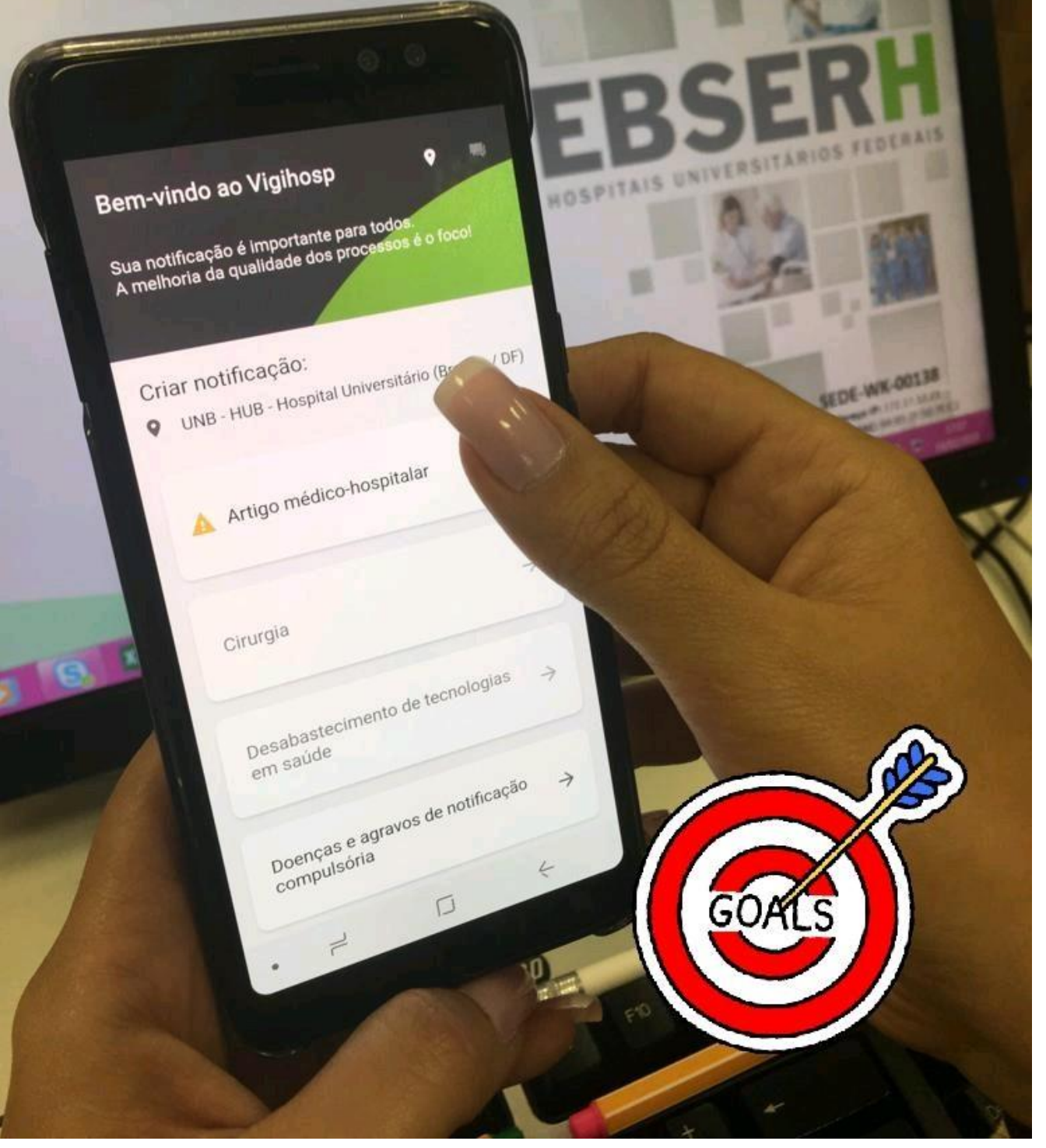




\section{RESULTADOS}

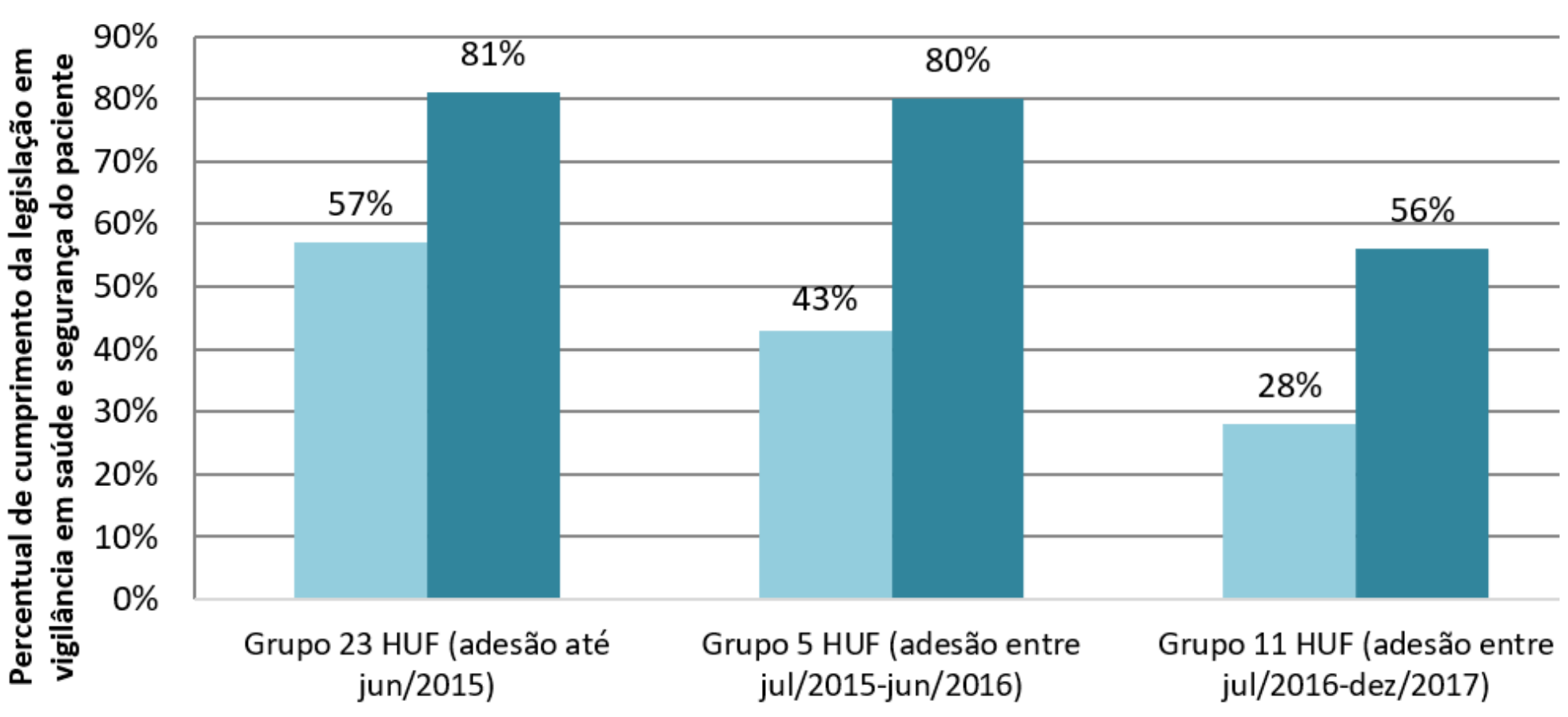

Grupos de Hospitais por tempo de adesão

Percentual de cumprimento da legislação em vigilância em saúde e segurança do paciente antes de entrar na rede Ebserh (antes do Programa de Segurança do Paciente) e em outubro de 2018 ( $n=40$ hospitais universitários federais). Fonte: Serviço de Gestão da Qualidade. 2018. 


\section{RESULTADOS}

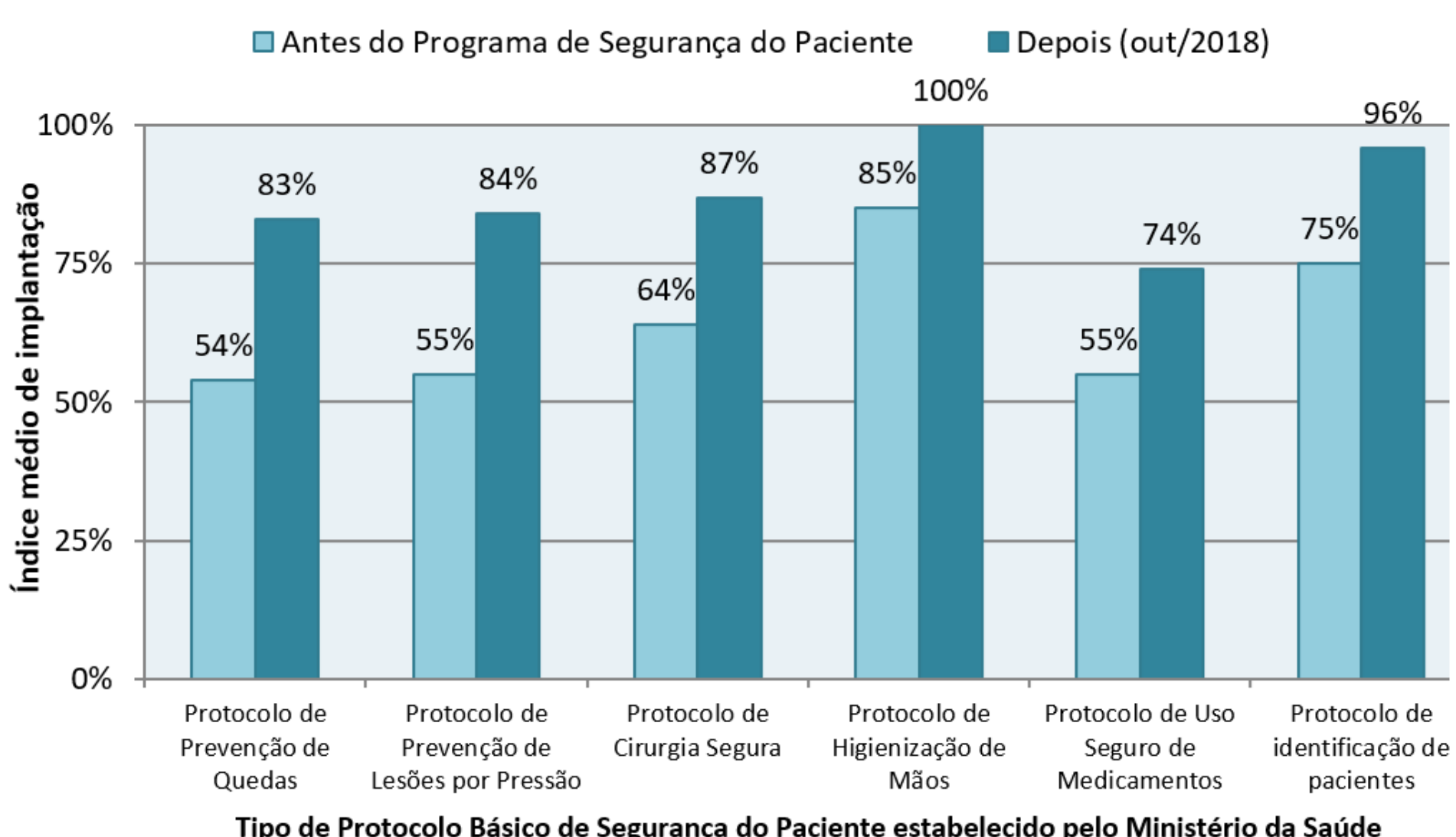

Índice médio de implantação dos protocolos básicos de segurança do paciente antes de entrar na rede Ebserh (antes do Programa de Segurança do Paciente) e em outubro de 2018 ( $n=40$ hospitais universitários federais). Fonte: Serviço de Gestão da Qualidade. 2018. 
- Taxa de mortalidade institucional (média)

_- Índice de Implantação do Programa Ebserh de Segurança do paciente (média)

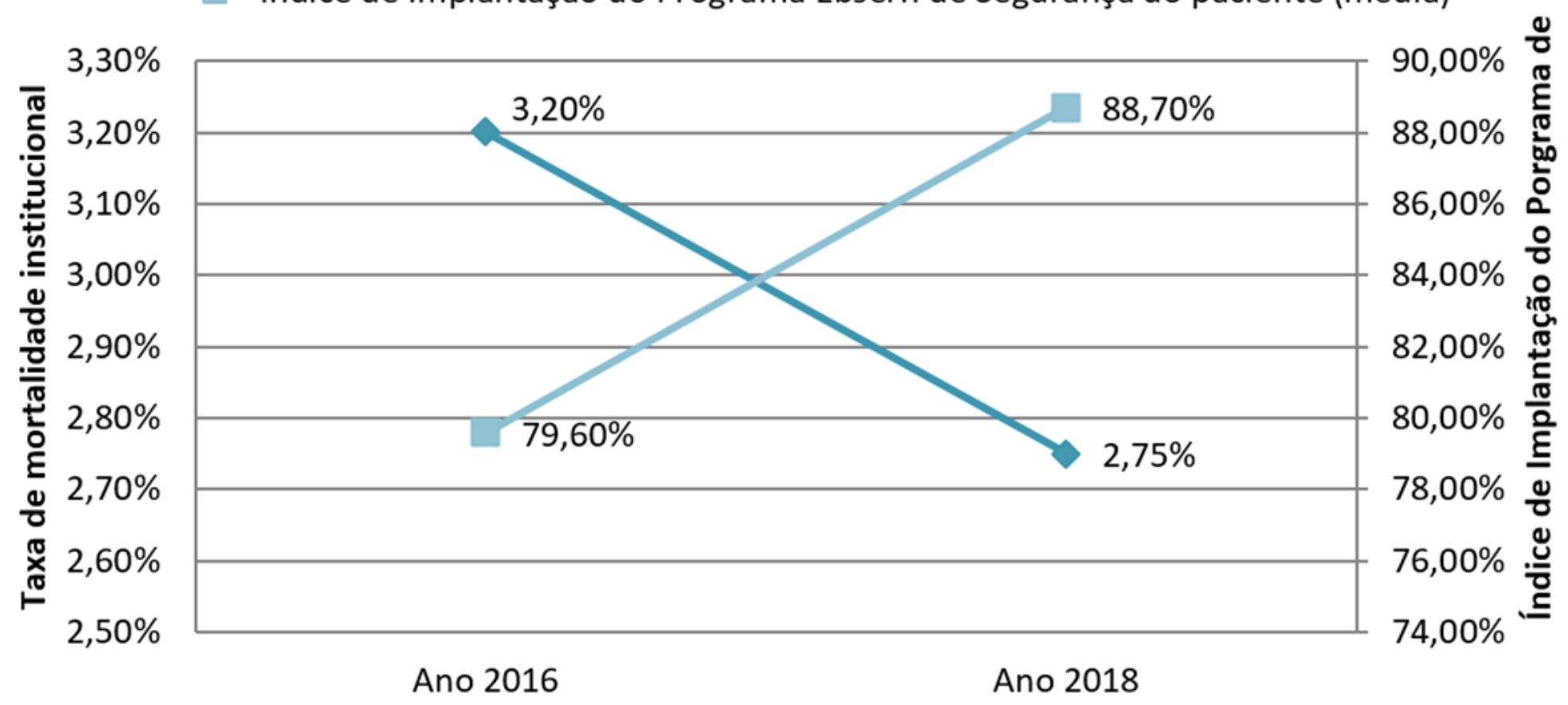

Comparação entre a média do índice de implantação do Programa Ebserh de Segurança do Paciente e a média da taxa de mortalidade institucional nos 16 hospitais universitários federais que mantiveram dados atualizados em nosso painel online de indicadores entre os anos de 2016 e 2018. Fonte: Serviço de Gestão da Qualidade. 2018. 


\section{CONCLUSÕES Mapa estratégico da Ebserh 2018-2022}

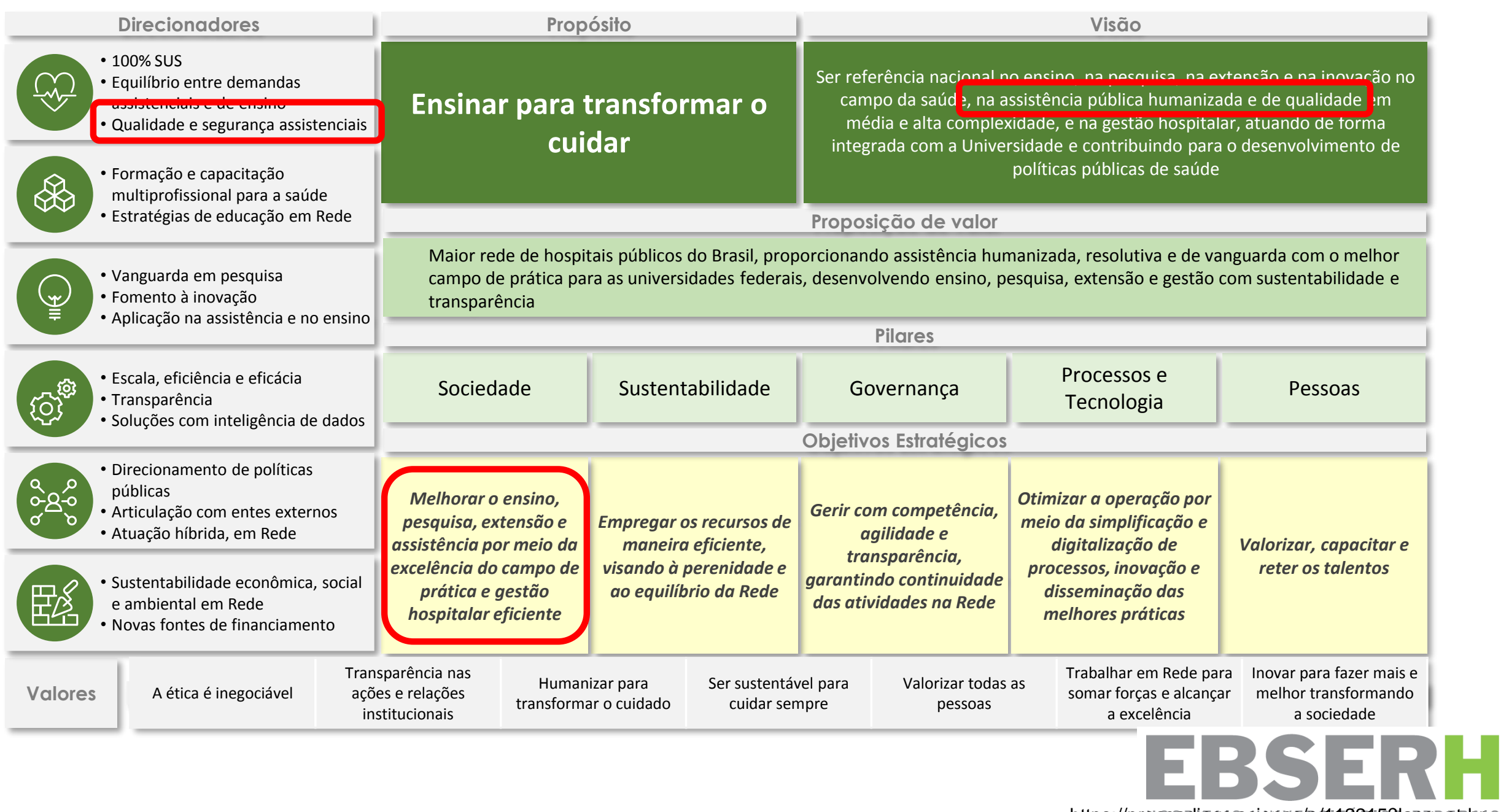




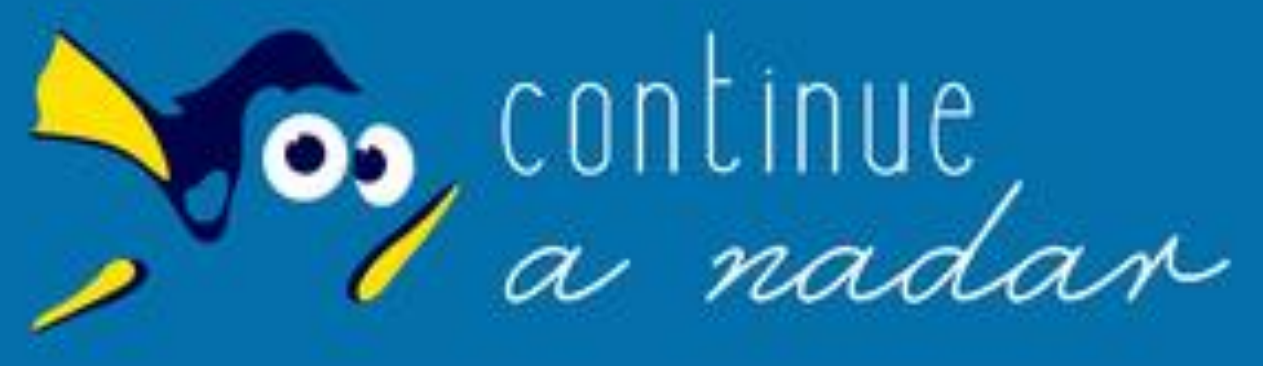

EBSERH【 Quali ఇ2 OBRIGADA! helane.capuch@@unb.br 